\title{
Breast Cancer Detection Research
}

National Cancer Institute

\section{Source}

National Cancer Institute. Breast Cancer Detection Research. NCI Thesaurus. Code

C15775.

Research project involving detection of breast tumors (screening, diagnosis clinical trials), development or refinement of diagnostic techniques or devices, education or promotion of breast cancer detection. 